\title{
Sunitinib-Induced Hypothyroidism and Survival in Pancreatic Neuroendocrine Tumors
}

Authors

Annie Mathew, Dagmar Führer, Harald Lahner

\begin{abstract}
Affiliation
Department of Endocrinology, Diabetes and Metabolism and Division of Laboratory Research, University Hospital Essen, University of Duisburg-Essen, Essen, Germany
\end{abstract}

Key words

pancreatic neuroendocrine tumor, neuroendocrinology, predictive factor, tyrosine kinase inhibitor, survival

received 06.08.2021

accepted after revision $\quad 26.09 .2021$

Bibliography

Horm Metab Res 2021; 53: 794-800

DOI 10.1055/a-1658-3077

ISSN 0018-5043

(c) 2021. Thieme. All rights reserved.

Georg Thieme Verlag KG, Rüdigerstraße 14,

70469 Stuttgart, Germany

Correspondence

Harald Lahner

Department of Endocrinology, Diabetes and Metabolism

and Division of Laboratory Research

Endocrine Tumor Center at WTZ/Comprehensive Cancer

Center and ENETS Center of Excellence

University Hospital Essen

University of Duisburg-Essen

Hufelandstraße 55

45147 Essen

Germany

Tel.: + 49/201/723 6405

harald.lahner@uk-essen.de

\section{ABSTRACT}

Sunitinib has been approved for the treatment of pancreatic neuroendocrine tumors, renal-cell carcinoma, and gastrointestinal stromal tumors. The elevation of thyroid-stimulating hormone serum levels is a common side effect. Studies suggest a correlation between sunitinib-induced hypothyroidism and treatment outcome in patients with renal-cell carcinoma and gastrointestinal stromal tumors. This study assessed whether sunitinib-induced hypothyroidism is a predictive marker of the objective response rate, progression-free survival, and overall survival in pancreatic neuroendocrine tumor patients. Twenty-nine patients treated with sunitinib for advanced pancreatic neuroendocrine tumors were included. The incidence of sunitinib-induced hypothyroidism was $33 \%$. The median progression-free survival of patients who developed hypothyroidism was 16 months (95\% confidence interval: 6.2-25.8 months) as compared with six months among euthyroid patients ( $95 \%$ confidence interval: $0.1-12.2$ months) $(p=0.02$ ). The median overall survival was 77 months ( $95 \%$ confidence interval: 31.4-122.6 months) in hypothyroid patients but 12 months (95\% confidence interval: 5.9-18.1 months) in subjects with euthyroidism $(p=0.001)$. The median overall survival from the time of initial diagnosis ranged from 247 months in patients with hypothyroidism to 65 months in euthyroid subjects $(p=0.015)$. Elevated thyroid-stimulating hormone levels are a prognostic biomarker of improved outcomes of sunitinib therapy in pancreatic neuroendocrine tumor patients.

\section{Introduction}

Differentiated pancreatic neuroendocrine tumors (PanNETs) are rare neoplasms that are suggested in the literature to have an increasing annual incidence of 0.48 per 100000 people [1]. At presentation, $60-80 \%$ of affected patients show unresectable disease due to local extension or metastases and, hence, palliative interventions may be offered instead [2,3]. The median survival of distant-stage PanNETs has improved up to 60 months, possibly re- flecting the progress made in therapeutic development [1]. Current treatments for advanced disease include molecular-targeted agents, streptozocin-based chemotherapy, mammalian target of rapamycin (mTOR) inhibitors, somatostatin analogs (SSAs), peptide-receptor radionuclide therapy (PRRT), and liver-directed treatments. However, the optimal therapy algorithm has not yet been defined due to a persisting lack of comparative studies [4]. 
As PanNETs are highly vascularized tumors, the dysregulation of vascular endothelial growth factor (VEGF), platelet-derived growth factor (PDGF), and their receptors has been suggested to play a major role in tumor growth and angiogenesis. The inhibition of angiogenesis would therefore be expected to trigger the growth inhibition of these tumors. Sunitinib, an oral multitarget tyrosine kinase inhibitor of, among others, the VEGF receptor, was approved for the treatment of advanced PanNETs in 2011. However, sunitinib-induced hypothyroidism has been reported in patients with gastrointestinal stromal tumor (GIST) and renal cell carcinoma (RCC) $[5,6]$. While the exact mechanism of this adverse event is not fully understood, various effects such as the inhibition of thyroid peroxidase activity, blockage of iodine uptake, blockage of thyroid-stimulating hormone (TSH) receptor, or alterations in thyroxine/triiodothyronine (T4/T3) metabolism have been proposed as possible underlying causes [7-9]. To what extent the development of sunitinib-induced hypothyroidism impacts the therapeutic outcome is not clear yet. A correlation between sunitinib-induced hypothyroidism and prolonged survival has been reported in some RCC studies and not in others [10-15]. Considering PanNETs, no data yet exist concerning the clinical significance of sunitinib-induced hypothyroidism. Therefore, we put forth for assessment the hypothesis that sunitinib-induced hypothyroidism enhances the response rate, progression-free survival (PFS), and overall survival (OS) in patients with advanced PanNETs.

\section{Patients and Methods}

Patients were identified from our prospective NET database at the European Neuroendocrine Tumor Society (ENETS) Centre of Excellence, Department of Endocrinology, Diabetes and Metabolism, University Hospital Essen. Eligible patients included those with histologically confirmed, differentiated, locally advanced or metastatic PanNETs and current sunitinib therapy usage between January 1 , 2011 and May 1, 2020 with all records located at our endocrine tumor center. Patients with a positive history of thyroid dysfunction or levothyroxine substitution were excluded from further analysis. Patients received sunitinib $37.5 \mathrm{mg}$ daily according to the standard schedule for PanNET treatment. All patients were tested for thyroid function within four weeks before starting sunitinib and again after three to six months of use. According to our institutional laboratory, the normal range of TSH serum concentration was 0.3-3.0 mIU/l, which was measured using a sandwich-immunoassay with chemiluminescence on the ADVIA Centaur XP platform (REF 06491080, Siemens Healthcare Diagnostics, Tarrytown, NY, USA). Hypothyroidism was considered to be present if the TSH concentration exceeded the upper limit of normal (ULN).

Data are reported as the number of patients (percentage of the group) for categories and median (lower-upper quartiles) for quantitative variables, unless otherwise stated. OS was computed as the time from treatment initiation with sunitinib to death from any cause. PFS was determined from the start of treatment with sunitinib until disease progression or death. OS was estimated with the Kaplan-Meier method and compared with the log-rank test. A Cox proportional-hazards model was used to calculate hazard ratios and to assess independent predictors of OS. The tests were two-tailed and results at $p<0.05$ were interpreted as statistically significant. All statistical analysis was performed using the Statistical Package for the Social Sciences version 26.0 software program (IBM Corporation, Armonk, NY, USA).

\section{Ethics Approval}

Written informed patient consent and approval for data collection and analysis was obtained upon admission to our institution. The study was approved by the ethics committee of the medical faculty of the University Duisburg-Essen (18-8367-BO).

\section{Results}

\section{Patient characteristics}

We identified 29 consecutive patients ( 13 women and 16 men) receiving sunitinib therapy for advanced PanNETs. Two patients (one woman and one man) were on levothyroxine substitution at baseline and were excluded from further analysis. The remaining $27 \mathrm{pa}$ tients had a median age of 54 years (range: $27-82$ years) when commencing sunitinib therapy. Twenty patients (74\%) had grade 2 tumors according to the World Health Organization criteria [16]. Six patients (22\%) exhibited morphologically differentiated PanNETs, grade 3 (G3) with an elevated proliferative level of the marker Ki-67 of between 20 and $45 \%$ ( $\triangleright$ Table 1). Five patients (19\%) suffered from a functioning tumor [two malignant insulinomas and one each with gastrinoma, vipoma, and parathyroid hormone-related protein (PTHrP)oma]. Median follow-up time was 15 months [95\% confidence interval ( $\mathrm{Cl}): 10-33$ months] from the start of sunitinib therapy and 70 months ( $95 \% \mathrm{Cl}: 47-103$ months) from the point of initial PanNET diagnosis. At the time of analysis, 19 deaths (70\% of the cohort) had occurred. Concerning the median, sunitinib was the third line of therapy (range: second to fifth line of therapy). Chemotherapy had already been performed in 16 patients (59\%), 11 (41\%) had undergone therapy with mTOR inhibition (everolimus), 16 (59\%) had previously received PRRT, and 19 (70\%) had a history of SSA therapy. The pancreatic primary tumor was initially surgically removed in 14 patients (52\%). The median duration of illness until the start of sunitinib therapy was 40 months (95\% Cl: 28-62 months) ( Table 1). All included patients had morphologically progressive disease at the start of sunitinib therapy.

\section{Response to treatment}

All patients were evaluable for response. Disease control was achieved in 20 of 27 patients (74\%), 6 of whom (22\%) experienced a partial response (PR) and 14 of whom (52\%) demonstrated stable disease (SD). Seven (26\%) patients exhibited disease progression (PD) as their best response to sunitinib therapy. The median PFS was 10 months ( $95 \% \mathrm{Cl}$ : 7.07-12.93 months), while the median OS from the start of sunitinib therapy was 24 months (95\% Cl: 9.02-38.98 months). Separately, the median survival period from the initial diagnosis of PanNET was 79 months (95\% Cl: $41.62-$ 116.38 months). Following sunitinib, six of the deceased 19 patients had received one further therapy line (e. g., everolimus, chemotherapy, SSA, or PRRT); one patient had received another two lines (chemotherapy, SSA); and, in 12 patients, sunitinib was the final disease-specific therapy line. 


\section{Thyroid function during treatment}

Patients were tested to collect data on TSH serum levels within four weeks before the start of sunitinib treatment. The median TSH level in the cohort of 27 patients was $1.24 \mathrm{mIU} / \mathrm{l}$ (95\% Cl: 0.99-1.71 $\mathrm{mIU} / \mathrm{I})$. Thyroid function was reassessed as part of regular staging examinations, including for the first time three months after commencing treatment with sunitinib. An increase in the TSH serum level above the ULN (3.0 mIU/I) occurred in nine of 27 patients (33.3\%), with a median TSH level of $4.03 \mathrm{mIU} / \mathrm{l}$ (95\% Cl: 3.58-6.40
$\mathrm{mIU} / \mathrm{l})$ after a median exposure time-period to sunitinib of three months (95\% Cl: 3.0-17.0 months). While women were present in the hypothyroid group at a significantly higher number than men, there were no differences between the groups with respect to other parameters ( $\triangleright$ Table 2 ). Four of the nine patients in the hypothyroid group (44.4\%) received levothyroxine substitution because of clinical symptoms so as to achieve a normal TSH value according to current guidelines [17].
- Table 1 Patient characteristics.

\begin{tabular}{|c|c|c|}
\hline Patient characteristics & No. & $\%$ \\
\hline Evaluable patients & 27 & 100 \\
\hline $\begin{array}{l}\text { Sex } \\
\text { Male } \\
\text { Female }\end{array}$ & $\begin{array}{l}15 \\
12\end{array}$ & $\begin{array}{l}56 \\
44\end{array}$ \\
\hline $\begin{array}{l}\text { Age at diagnosis (years) } \\
\text { Median (range) }\end{array}$ & $54(27-82)$ & \\
\hline $\begin{array}{l}\text { Age at therapy start (years) } \\
\text { Median (range) }\end{array}$ & $59(28-83)$ & \\
\hline $\begin{array}{l}\text { Disease duration at therapy start (months) } \\
\text { Median (range) }\end{array}$ & $40(4-213)$ & \\
\hline $\begin{array}{l}\text { Ki67-proliferation index } \\
<3 \% \\
3-20 \% \\
>20 \%\end{array}$ & $\begin{array}{l}1 \\
20 \\
6\end{array}$ & $\begin{array}{l}4 \\
74 \\
22\end{array}$ \\
\hline $\begin{array}{l}\text { Functioning NET } \\
\text { Yes } \\
\text { No }\end{array}$ & $\begin{array}{l}5 \\
22\end{array}$ & $\begin{array}{l}19 \\
81\end{array}$ \\
\hline $\begin{array}{l}\text { Hypothyroidism during therapy } \\
\text { Yes } \\
\text { No }\end{array}$ & $\begin{array}{l}9 \\
18\end{array}$ & $\begin{array}{l}33 \\
67\end{array}$ \\
\hline $\begin{array}{l}\text { Progression-free survival (months) } \\
\text { Median }(95 \% \mathrm{Cl})\end{array}$ & $10(7-13)$ & \\
\hline $\begin{array}{l}\text { Response rate (best response) } \\
\text { PR } \\
\text { SD } \\
\text { PD }\end{array}$ & $\begin{array}{l}6 \\
14 \\
7\end{array}$ & $\begin{array}{l}22 \\
52 \\
26\end{array}$ \\
\hline $\begin{array}{l}\text { Surgical removal of the primary tumor } \\
\text { Yes } \\
\text { No }\end{array}$ & $\begin{array}{l}14 \\
13\end{array}$ & $\begin{array}{l}52 \\
48\end{array}$ \\
\hline $\begin{array}{l}\text { Previous therapy lines } \\
\leq 2 \\
3-4\end{array}$ & $\begin{array}{l}17 \\
10\end{array}$ & $\begin{array}{l}63 \\
37\end{array}$ \\
\hline $\begin{array}{l}\text { Previous chemotherapy } \\
\text { Yes } \\
\text { (Streptozocin-based) } \\
\text { (Temozolomide/capecitabine) } \\
\text { No }\end{array}$ & $\begin{array}{l}21 \\
(20) \\
(5) \\
6\end{array}$ & $\begin{array}{l}78 \\
(74) \\
(19) \\
22\end{array}$ \\
\hline $\begin{array}{l}\text { Previous PRRT } \\
\text { Yes } \\
\text { No }\end{array}$ & $\begin{array}{l}19 \\
8\end{array}$ & $\begin{array}{l}70 \\
30\end{array}$ \\
\hline $\begin{array}{l}\text { Previous everolimus } \\
\text { Yes } \\
\text { No }\end{array}$ & $\begin{array}{l}15 \\
12\end{array}$ & $\begin{array}{l}56 \\
44\end{array}$ \\
\hline
\end{tabular}

- Table 2 Comparison of the hypothyroid and euthyroid groups.

\begin{tabular}{|c|c|c|c|}
\hline & $\begin{array}{l}\text { TSH level } \\
\text { elevated } \\
n=9\end{array}$ & $\begin{array}{l}\text { TSH level } \\
\text { normal } \\
n=18\end{array}$ & p-Value \\
\hline $\begin{array}{l}\text { Sex } \\
\text { Male } \\
\text { Female }\end{array}$ & $\begin{array}{l}2 \\
7\end{array}$ & $\begin{array}{l}13 \\
5\end{array}$ & 0.037 \\
\hline $\begin{array}{l}\text { Age at start of therapy } \\
\text { (years), median (range) }\end{array}$ & $58.0(28-74)$ & $59.5(42-83)$ & $0.257^{*}$ \\
\hline $\begin{array}{l}\text { Ki-67 index (\%), median } \\
\text { (range) }\end{array}$ & $5(4-30)$ & $10(2-45)$ & $0.307^{*}$ \\
\hline $\begin{array}{l}\text { Time since diagnosis } \\
\text { (months), median (range) }\end{array}$ & $3(0-17)$ & $3(1-11)$ & $0.619^{*}$ \\
\hline $\begin{array}{l}\text { Therapy line, median } \\
\text { (range) }\end{array}$ & $3(2-5)$ & $3(2-5)$ & $0.414^{*}$ \\
\hline $\begin{array}{l}\text { Response to treatment } \\
\text { Yes }(C R, P R) \\
\text { No }(S D, P D)\end{array}$ & $\begin{array}{l}4 \\
5\end{array}$ & $\begin{array}{l}2 \\
16\end{array}$ & 0.136 \\
\hline $\begin{array}{l}\text { Disease control ** } \\
\text { Yes (CR, PR, SD) } \\
\text { No (PD) }\end{array}$ & $\begin{array}{l}9 \\
0\end{array}$ & $\begin{array}{l}11 \\
7\end{array}$ & 0.059 \\
\hline $\begin{array}{l}\text { Functioning tumor } \\
\text { Yes } \\
\text { No }\end{array}$ & $\begin{array}{l}1 \\
8\end{array}$ & $\begin{array}{l}4 \\
14\end{array}$ & 0.636 \\
\hline $\begin{array}{l}\text { Previous surgery } \\
\text { Yes } \\
\text { No }\end{array}$ & $\begin{array}{l}7 \\
2\end{array}$ & $\begin{array}{l}7 \\
11\end{array}$ & 0.103 \\
\hline $\begin{array}{l}\text { Previous CTx } \\
\text { Yes } \\
\text { No }\end{array}$ & $\begin{array}{l}3 \\
6\end{array}$ & $\begin{array}{l}13 \\
5\end{array}$ & 0.097 \\
\hline $\begin{array}{l}\text { Previous everolimus } \\
\text { Yes } \\
\text { No }\end{array}$ & $\begin{array}{l}5 \\
4\end{array}$ & $\begin{array}{l}6 \\
12\end{array}$ & 0.411 \\
\hline $\begin{array}{l}\text { Previous SSA } \\
\text { Yes } \\
\text { No }\end{array}$ & $\begin{array}{l}7 \\
2\end{array}$ & $\begin{array}{l}12 \\
6\end{array}$ & 0.676 \\
\hline $\begin{array}{l}\text { Previous PRRT } \\
\text { Yes } \\
\text { No }\end{array}$ & $\begin{array}{l}4 \\
5\end{array}$ & $\begin{array}{l}12 \\
6\end{array}$ & 0.411 \\
\hline
\end{tabular}

Values are presented as absolute numbers, unless otherwise stated. p-Value: Fisher's exact test, otherwise specified. CR: Complete remission; PR: Partial remission; SD: Stable disease; PD: Progressive disease; CTx: Chemotherapy; SSA: Somatostatin-analogue; PRRT: Peptide-radio-receptor-therapy. ${ }^{*}$ Mann-Whitney U-test; ${ }^{*}$ * Best response. 


\section{Thyroid function and response to treatment}

In the hypothyroid group, the objective response rate (ORR) was $44.4 \%$ (4/9 patients), while the ORR in the euthyroid group corresponded to $11.1 \%$ (2/18 patients). The disease control rate (DCR; $C R+P R+S D$, best response) reached $100 \%$ in the hypothyroid group (9/9 patients) and $61.1 \%$ in the euthyroid group (11/18 patients). However, this difference was not statistically significant ( Table 2).

\section{Impact of hypothyroidism on PFS and OS}

There was a significant association between an elevated TSH level and PFS after commencing sunitinib therapy. The median PFS was 16 months (95\% Cl: 6.2-25.8 months) in patients with hypothyroidism versus six months ( $95 \% \mathrm{Cl}: 0.1-12.2$ months) in subjects with normal thyroid function ( $\triangleright$ Fig. 1 ) for a difference that was statistically significant with a p-value of 0.02 (log-rank test). Further, the hazard ratio (HR) was 0.35 (95\% Cl: 0.14-0.92; $\mathrm{p}=0.03$ ) for hypothyroidism. However, the increase in TSH level had an even more prominent association with OS from the initiation of sunitinib therapy ( $\triangleright$ Fig. 2 ). The median survival was 77 months ( $95 \%$ Cl: $31.4-$ 122.6 months) in patients who experienced an elevation in their TSH level as compared with 12 months ( $95 \%$ Cl: 5.9-18.1 months) for those with euthyroidism ( $p=0.001$, log-rank test). Here, the HR was 0.15 (95\% Cl: $0.04-0.54 ; p=0.004$ ) for hypothyroidism. The prognostic significance of the development of hypothyroidism during the use of sunitinib therapy was also evident in the OS from the point of initial PanNET diagnosis onward ( $\triangleright$ Fig. 3). While the hypothyroid cohort had a median OS of 247 months, the median OS was 65 months in the euthyroid patient group ( $95 \% \mathrm{Cl}: 48.1-81.9$ months; $\mathrm{p}=0.015$, log-rank test), with an $\mathrm{HR}$ of 0.237 ( $95 \% \mathrm{Cl}: 0.07-0.83$; $p=0.024$ ) for hypothyroidism. Several other clinical and laboratory variables were tested to elucidate their impact on both PFS and OS. In the univariate analysis, the Ki-67 index had an impact on PFS (HR:
1.04, $95 \% \mathrm{Cl}: 1.001-1.073 ; \mathrm{p}=0.044)$, whereas functionality (HR: 4.608, $95 \% \mathrm{Cl}: 1.560-13.609 ; \mathrm{p}=0.006)$, therapy line (HR: 1.620 , $95 \% \mathrm{Cl}: 1.017-2.580 ; \mathrm{p}=0.042$ ), and previous chemotherapy (HR: $2.949,95 \% \mathrm{Cl}: 1.126-7.726 ; \mathrm{p}=0.028$ ) had an impact on OS from the start of sunitinib therapy. In the multivariate analysis, hypothyroidism (HR: $0.05,95 \% \mathrm{Cl}: 0.009-0.298 ; \mathrm{p}=0.001$ ) and functionality (HR: $17.90,95 \% \mathrm{Cl}: 1.97-162.61 ; \mathrm{p}=0.01$ ) remained associated with OS.

\section{Discussion}

In the present study, we analyzed the correlation between sunitinib-induced hypothyroidism and the response to treatment among patients with PanNETs. The effect of sunitinib-induced hypothyroidism has been described previously in RCC and GIST with conflicting results [7, 10-15].

Here, we found that $33 \%$ of the patients treated with sunitinib for metastatic PanNETs developed hypothyroidism, which confirms the occurrence of an effect of sunitinib on thyroid function in these individuals. Heterogeneous incidence rates of sunitinib-induced hypothyroidism ranging from $36 \%$ to $85 \%$ have been reported in RCC and GIST [5, 6], notably, the variable prevalence of thyroid dysfunction at study entry, limited evaluability, and different definitions of the ULN of the TSH level could contribute to this significant discrepancy. In our study, all patients with a history of thyroid dysfunction or who were on levothyroxine substitution were excluded and all remaining subjects were evaluable. Our cutoff for the ULN of TSH (3.0 mIU/I) was chosen based on the long-term reference range adopted for the diagnostic evaluation of patients of our institution.

In this study, the ORR of the hypothyroid PanNET group was $44 \%$, which is in contrast with that of $11 \%$ in the euthyroid group. This result agrees with findings in RCC patients. Bozkurt et al. re-

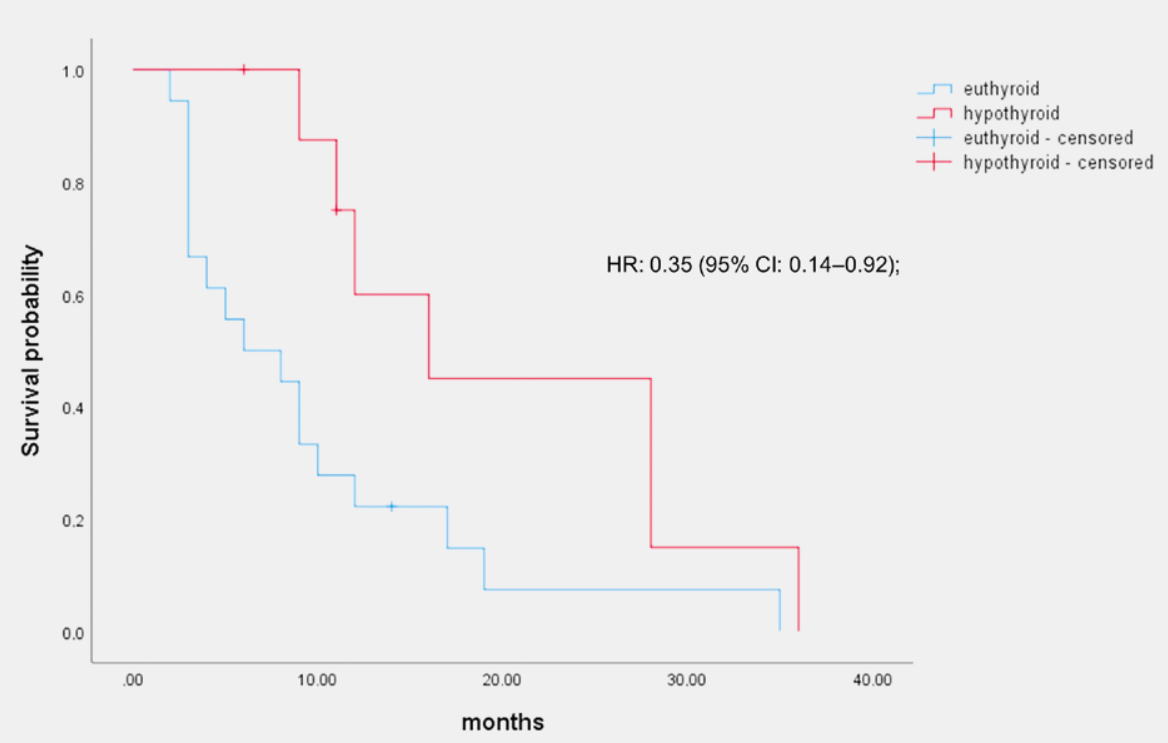

- Fig. 1 Kaplan-Meier estimate. PFS (months) in patients who developed hypothyroidism during sunitinib treatment (red line) and those who remained in a euthyroid state (blue line). 


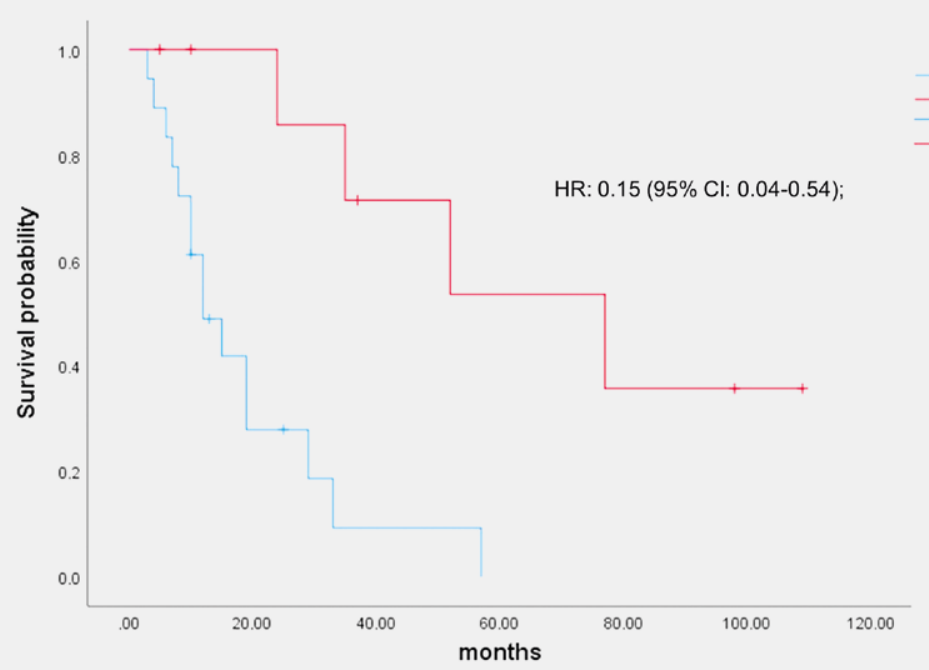

- Fig. 2 Kaplan-Meier estimate. OS (months) after therapy initiation in patients who developed hypothyroidism during sunitinib treatment (red line) and those who did not (blue line).

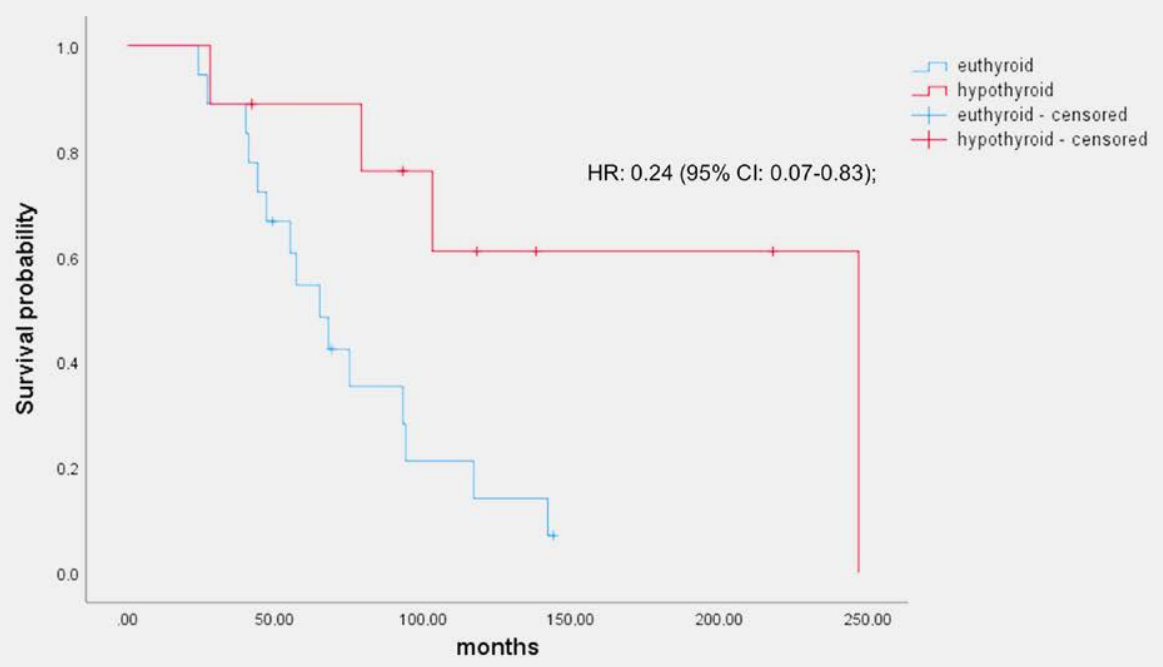

- Fig. 3 Kaplan-Meier estimate. OS (months) after initial PanNET diagnosis in patients who developed hypothyroidism during sunitinib treatment (red line) and those who did not (blue line).

ported a similar ORR of $47 \%$ among hypothyroid RCC patients as opposed to $14 \%$ in the euthyroid group [18]. Meanwhile, in the study by Schmidinger et al., the ORRs were $28 \%$ and $3 \%$ for the hypo-and euthyroid RCC groups [12]. Concerning PanNETs, available data regarding the ORR of sunitinib remain limited. A phase III study reported an ORR of $9 \%$ in 86 PanNET patients [19] as compared with that of $22 \%$ in our study. Interestingly, most individuals in the sunitinib arm of the aforementioned phase III study remained as euthyroid patients, with TSH elevation reported only in six out of 86 patients ( $7 \%$ ). In this context, the ORR of $11 \%$ in the euthyroid group in our study corresponds to that of $9 \%$ among the mainly euthyroid patients of said phase III study. This perception is confirmed when considering the disease control rate, i. e., patients with at least SD $(C R+P R+S D$, best response $)$. We observed disease stabilization in all of the patients in the hypothyroid group as compared with in 11 of 18 patients (61\%) in the euthyroid group. A similar $72 \%$ DCR was observed in the phase III study [19].

The overall PFS of 10 months among our subjects was significantly affected by sunitinib-associated thyroid function. While euthyroid patients showed a median PFS of six months, such was prolonged to 16 months in hypothyroid individuals. Meanwhile, in the prior randomized phase III study, a median PFS of 11.4 months was observed [19]. Interestingly, the differences in PFS reflects variations in the DCR as well. As the Kaplan-Meier curves of eu-and hy- 
> Table 3 Incidence of hypothyroidism and survival in clinical studies with sunitinib for RCC and GIST.

\begin{tabular}{|c|c|c|c|c|c|c|}
\hline Year & Entity & Study design & $\mathbf{n}$ & $\begin{array}{l}\text { Hypothyroidism n } \\
\text { (\%) }\end{array}$ & $\begin{array}{l}\text { Survival hypo- vs. } \\
\text { euthyroidism (months) }\end{array}$ & Reference \\
\hline 2006 & GIST & Prospective & 42 & $15(36 \%)$ & - & Desai et al. [5] \\
\hline 2007 & GIST & Prospective & 24 & $17(71 \%)$ & - & Mannavola et al. [8] \\
\hline 2007 & GIST & Retrospective & 40 & $21(53 \%)$ & - & Wong et al. [9] \\
\hline 2008 & GIST, RCC & Prospective & 59 & $36(61 \%)$ & - & Wolter et al. [21] \\
\hline 2011 & $\mathrm{RCC}$ & Retro-and prospective & 66 & $56(85 \%)$ & - & Rini et al. [6] \\
\hline 2011 & $\mathrm{RCC}$ & Prospective & 17 & $9(53 \%)$ & - & Shinohara et al. [24] \\
\hline 2011 & $\mathrm{RCC}$ & Prospective & 45 & $32(71 \%)$ & PFS 11.8 vs. 10.8 & Schmidinger et al. [13] \\
\hline 2012 & $\mathrm{RCC}$ & Prospective & 22 & $13(59 \%)$ & PFS 8.6 vs. 7.0 & Baldazzi et al. [10] \\
\hline 2012 & RCC & Prospective & 102 & $51(50 \%)$ & PFS 18.9 vs. 15.9 & Sabatier et al. [12] \\
\hline 2012 & $\mathrm{RCC}$ & Retrospective & 31 & $16(52 \%)$ & $\begin{array}{l}\text { PFS } 12.2 \text { vs. } 9.4 \\
\text { OS } 22.4 \text { vs. } 13.9\end{array}$ & Sella et al. [14] \\
\hline 2019 & RCC & Retrospective & 70 & $35(50 \%)$ & $\begin{array}{l}\text { PFS } 11.9 \text { vs. } 8.8 \\
\text { OS } 37.2 \text { vs. } 13.2\end{array}$ & Vasileiadis et al. [15] \\
\hline
\end{tabular}

pothyroid patients run almost parallel, the statistical difference refers mainly to the rate of nonresponse at three months after commencing sunitinib. Considering findings from our subgroup of euthyroid patients, the PFS in the phase III study with a predominance of euthyroid patients was longer. Different preconditions between controlled studies and real-world data, such as the number of preceding therapy lines or comorbidities, may lead to this variation. In other tumor entities, sunitinib-induced hypothyroidism was also associated with prolonged PFS, but not to the extent that we observed in PanNET patients ( Table 3 ).

The median OS in PanNET patients from the start of sunitinib therapy was significantly improved from 12 to 77 months in our patients who developed hypothyroidism. This effect was so pronounced that it was reflected in the length of OS since PanNET diagnosis, resulting in 65 months in the euthyroid group and 247 months in patients who experienced sunitinib-induced hypothyroidism at any time during their therapy course. The median OS from the time of PanNET diagnosis in our cohort was 79 months and, thus, longer than the reported 60 months for the appropriate group within the SEER database [1]. Most likely, this is because newer therapy options like sunitinib or everolimus were not yet available during the observation period of the SEER data (20002012). Our findings correlate with those of Buda-Nowak et al. who analyzed thyroid dysfunction and treatment outcome in $27 \mathrm{pa}-$ tients with metastatic RCC [20]; these authors reported that the patients who developed hypothyroidism had longer median PFS than patients with normal thyroid function at 28.3 months versus 9.8 months. Meanwhile, the inclusion of GIST patients led to median PFS periods of 10.3 and 3.6 months with and without thyroid function abnormalities; there was a nonsignificant trend toward an improvement in the OS [21].

Several causes of thyroid dysfunction during tyrosine kinase inhibitor (TKI) treatment have been discussed to date. The study by Kappers et al. suggested that sunitinib induces hypothyroidism due to the induction of type 3 deiodinase activity as well as thyroid cap- illary regression [7]. The inhibition of VEGF signaling with sunitinib-induced thyroid dysfunction occurred in both human patients and rats and was due to capillary regression in the thyroid and alterations in the T4/T3 metabolism. It seems likely that, in patients with longer durations of treatment, the sunitinib-induced rarefaction induces thyroid tissue injury and, eventually, tissue destruction [7].

A protective effect of hypothyroidism may also be explained by thyroid hormone activity, mainly T4, on cancer-cell proliferation. Antiapoptotic effects of thyroid hormone via interaction with integrin family and epidermal growth factor, insulin-like growth factor 1 receptor phosphorylation, antiapoptotic pathways (mitogen-activated protein kinase), and angiogenesis via fibroblast growth factor have been described. Latteyer et al. showed that thyroid hormones itself can influence non-small-cell lung cancer progression by enhancing neovascularization via $\alpha v \beta 3$, underlining that levothyroxine substitution could be harmful to cancer patients [22]. Hercbergs et al. and others suggest T3 substitution occurs in cancer patients due to the differentiation between the significant pro-oncogenic mitogenicity of physiologic T4 levels and the significantly lower mitogenicity of physiologic T3 levels in human and rodent tumor models, such as glioma and non-small-cell lung carcinoma cells [23]. These studies highlight the divergence between the predominantly metabolic actions with reduced oncogenic potential of T3 and the pro-oncogenic actions of T4. The divergence constitutes the option of replacing circulating $\mathrm{T} 4$ with exogenous T3 in cancer patients [22].

Limitations of the present study included its relatively small sample size and its retrospective design, both of which reflect the rarity of the disease in question. Furthermore, the implementation of systematic thyroid ultrasonography and antibody assessments could be useful for understanding the mechanism by which sunitinib induces thyroid dysfunction. These factors should be focused on by future multicenter studies. 


\section{Conclusion}

In patients with metastatic PanNETs, the onset of sunitinib-induced hypothyroidism is associated with a favorable outcome and significantly improved survival. Consequently, thyroid function should be evaluated regularly during treatment with sunitinib.

\section{Conflict of Interest}

The authors declare that they have no conflict of interest.

\section{References}

[1] Dasari A, Shen C, Halperin D et al. Trends in the incidence, prevalence, and survival outcomes in patients with neuroendocrine tumors in the United States. JAMA Oncol 2017; 3: 1335-1342

[2] Falconi M, Eriksson B, Kaltsas $G$ et al. ENETS consensus guidelines update for the management of patients with functional pancreatic neuroendocrine tumors and non-functional pancreatic neuroendocrine tumors. Neuroendocrinology 2016; 103: 153-171

[3] Panzuto F, Boninsegna L, Fazio N et al. Metastatic and locally advanced pancreatic endocrine carcinomas: Analysis of factors associated with disease progression. J Clin Oncol 2011; 29: 2372-2377

[4] Halfdanarson TR, Strosberg JR, Tang L et al. The North American neuroendocrine tumor society consensus guidelines for surveillance and medical management of pancreatic neuroendocrine tumors. Pancreas 2020; 49: 863-881

[5] Desai ], Yassa L, Marqusee E et al. Hypothyroidism after sunitinib treatment for patients with gastrointestinal stromal tumors. Ann Intern Med 2006; 145: 660-664

[6] Rini BI, Tamaskar I, Shaheen P et al. Hypothyroidism in patients with metastatic renal cell carcinoma treated with sunitinib. J Natl Cancer Inst 2007; 99: 81-83

[7] Kappers MH, van Esch JH, Smedts FM et al. Sunitinib-induced hypothyroidism is due to induction of type 3 deiodinase activity and thyroidal capillary regression. J Clin Endocrinol Metab 2011; 96: 3087-3094

[8] Mannavola D, Coco P, Vannucchi G et al. A novel tyrosine-kinase selective inhibitor, sunitinib, induces transient hypothyroidism by blocking iodine uptake. J Clin Endocrinol Metab 2007; 92: 3531-3534

[9] Wong E, Rosen LS, Mulay M et al. Sunitinib induces hypothyroidism in advanced cancer patients and may inhibit thyroid peroxidase activity. Thyroid 2007; 17: 351-355

[10] Baldazzi V, Tassi R, Lapini A et al. The impact of sunitinib-induced hypothyroidism on progression-free survival of metastatic renal cancer patients: A prospective single-center study. Urol Oncol 2012; 30: 704-710
[11] Riesenbeck LM, Bierer S, Hoffmeister I et al. Hypothyroidism correlates with a better prognosis in metastatic renal cancer patients treated with sorafenib or sunitinib. World J Urol 2011; 29: 807-813

[12] Sabatier R, Eymard JC, Walz J et al. Could thyroid dysfunction influence outcome in sunitinib-treated metastatic renal cell carcinoma? Ann Oncol 2012; 23: 714-721

[13] Schmidinger M, Vogl UM, Bojic M et al. Hypothyroidism in patients with renal cell carcinoma: blessing or curse? Cancer 2011; 117: 534-544

[14] Sella A, Hercbergs AH, Hanovich E et al. Does sunitinib-induced hypothyroidism play a role in the activity of sunitinib in metastatic renal cell carcinoma? Chemotherapy 2012; 58: 200-205

[15] Vasileiadis T, Chrisofos M, Safioleas M et al. lotampact of sunitinib-induced hypothyroidism on survival of patients with metastatic renal cancer. BMC Cancer 2019; 19: 407

[16] Lloyd RV, Klöppel G, Rosai ]. WHO Classification of Tumours of Endocrine Organs. IARC Press; 2017

[17] Garber JR, Cobin RH, Gharib H et al. Clinical practice guidelines for hypothyroidism in adults: cosponsored by the American association of clinical endocrinologists and the American thyroid association. Endocr Pract 2012; 18: 988-1028

[18] Bozkurt O, Karaca H, Hacibekiroglu I et al. Is sunitinib-induced hypothyroidism a predictive clinical marker for better response in metastatic renal cell carcinoma patients? J Chemother 2016; 28 : 230-234

[19] Raymond E, Dahan L, Raoul JL et al. Sunitinib malate for the treatment of pancreatic neuroendocrine tumors. N Engl J Med 2011; 364: 501-513

[20] Buda-Nowak A, Kucharz J, Dumnicka P et al. Sunitinib-induced hypothyroidism predicts progression-free survival in metastatic renal cell carcinoma patients. Med Oncol 2017; 34: 68

[21] Wolter P, Stefan C, Decallonne B et al. The clinical implications of sunitinib-induced hypothyroidism: a prospective evaluation. $\mathrm{Br}$ J Cancer 2008; 99: 448-454

[22] Latteyer S, Christoph S, Theurer $S$ et al. Thyroxine promotes lung cancer growth in an orthotopic mouse model. Endocr Relat Cancer 2019; 26: 565-574

[23] Hercbergs A, Davis PJ, Lin HY et al. Possible contributions of thyroid hormone replacement to specific behaviors of cancer. Biomed Pharmacother 2016; 84: 655-659

[24] Shinohara N, Takahashi M, Kamishima T et al. The incidence and mechanism of sunitinib-induced thyroid atrophy in patients with metastatic renal cell carcinoma. $\mathrm{Br}$ J Cancer 2011; 104: 241-247 